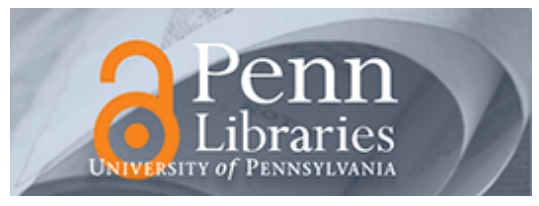

University of Pennsylvania

ScholarlyCommons

$12-1-1997$

\title{
A Phenomenological Variant of Ecological Systems Theory (PVEST): A self-organization perspective in context
}

Margaret Beale Spencer

University of Pennsylvania, marges@gse.upenn.edu

Davido Dupree

University of Pennsylvania

Tracey Hartmann

University of Pennsylvania

Follow this and additional works at: https://repository.upenn.edu/gse_pubs

Part of the Developmental Psychology Commons

\section{Recommended Citation}

Spencer, M. B., Dupree, D., \& Hartmann, T. (1997). A Phenomenological Variant of Ecological Systems Theory (PVEST): A self-organization perspective in context. Retrieved from https://repository.upenn.edu/ gse_pubs/4

Copyright Cambridge University Press. Reprinted from Development and Psychopathology, Volume 9, Issue 4, December 1997, pages 817-833.

This paper is posted at ScholarlyCommons. https://repository.upenn.edu/gse_pubs/4

For more information, please contact repository@pobox.upenn.edu. 


\title{
A Phenomenological Variant of Ecological Systems Theory (PVEST): A self- organization perspective in context
}

\author{
Abstract \\ A framework that emphasizes and integrates individuals' intersubjective experiences with \\ Bronfenbrenner's ecological systems theory (PVEST) is introduced and compared with self-organizational \\ perspectives. Similarities, differences and advantages of each framework are described. In a \\ demonstration of PVEST's utility, a subset of data from the 3rd year of a longitudinal study (14-to 16-year- \\ old middle adolescent African-Americans) is used for examining an achievement variable: negative \\ learning attitude. Explored separately by gender, a regression model that contained risk, stress, and a \\ reactive coping variable for the prediction of negative learning attitudes was investigated. For boys, stress \\ was an independent stressor across steps independent of the other variables entered; social support was \\ particularly important for males. For girls, not only was stress not important but it was also only the social \\ support variable, perceived unpopularity with peers, that was a significant predictor of girls' negative \\ learning attitude. Particularly for boys, the findings suggest critically important roles for teachers and \\ peers in the negative learning attitude of midadolescent economically disadvantaged African-American \\ students. \\ Disciplines \\ Developmental Psychology
}

\section{Comments}

Copyright Cambridge University Press. Reprinted from Development and Psychopathology, Volume 9, Issue 4, December 1997, pages 817-833. 


\title{
A Phenomenological Variant of Ecological Systems Theory (PVEST): A self- organization perspective in context
}

\author{
MARGARET BEALE SPENCER, DAVIDO DUPREE, \\ AND TRACEY HARTMANN \\ University of Pennsylvania
}

\begin{abstract}
A framework that emphasizes and integrates individuals' intersubjective experiences with Bronfenbrenner's ecological systems theory (PVEST) is introduced and compared with self-organizational perspectives. Similarities, differences and advantages of each framework are described. In a demonstration of PVEST's utility, a subset of data from the 3rd year of a longitudinal study (14- to 16-year-old middle adolescent African-Americans) is used for examining an achievement variable: negative learning attitude. Explored separately by gender, a regression model that contained risk, stress, and a reactive coping variable for the prediction of negative learning attitudes was investigated. For boys, stress was an independent stressor across steps independent of the other variables entered; social support was particularly important for males. For girls, not only was stress not important but it was also only the social support variable, perceived unpopularity with peers, that was a significant predictor of girls' negative learning attitude. Particularly for boys, the findings suggest critically important roles for teachers and peers in the negative learning attitude of midadolescent economically disadvantaged African-American students.
\end{abstract}

Across the life course, experiences in different cultural contexts (e.g., home, school, peer group, community) influence how one perceives oneself. This statement could simply mean that there is a relationship between life experiences and self-esteem. However, this assertion goes further than that. We assert that the processing of phenomena and experiences not only influences how much one feels valued or valuable (e.g., self-esteem), but it also influences how one gives meaning and significance to different aspects of oneself (e.g., abilities, physical attributes, behaviors, and

The research reported was supported by funds to the first author from several sources: The Spencer, W. T. Grant, and Ford Foundations, The Commonwealth Fund and the Social Science Research Council. Additional supplemental support was provided by the Annenberg Foundation.

Address correspondence and reprint requests to: Margaret Beale Spencer, University of Pennsylvania, Graduate School of Education, 3700 Walnut St., Philadelphia, PA 19104-6216. activities). More specifically, it is not merely the experience but one's perception of experiences in different cultural contexts that influences how one perceives oneself. Perceptual processes are dependent upon social-cognitive processes which aid in explaining the developmental variations in response. Consequent meaning making processes include the responsive coping methods or corrective problem-solving strategies pursued. The repetitiveness of the context-linked corrective problem-solving strategies (i.e., reactive coping methods) become linked to stable coping responses: one's emergent identity or selfprocesses. This is important because it is often these self-perceptions that temporally influence responses: they influence how one will adapt to the same cultural contexts across the life course. These generally stable self-perceptions will influence whether one uses or downplays certain abilities, emphasizes or draws attention away from certain physical at- 
tributes, adopts or suppresses certain behaviors, engages in or shies away from certain activities. Self-perceptions organize one's behaviors, thoughts, and actions. This is evident when cultural stereotypes become self-fulfilling prophecies. For instance, a young African-American male may take advantage of the knowledge that he is perceived by the larger society as violent and mischievous. That male may begin to behave more aggressively if he also perceives that aggressive behavior may increase his status among his peers.

Normative development themes, including subjective self-perceptual processes, increase in complexity because of the character and content of high risk environments associated with ethnicity and visibility for American minorities. These subjective processes are potentially, although not necessarily, damaging to "the self" particularly when they occur in chronically high risk contexts. For some, the chronic state of risk requires myriad modes of coping necessary to offset feelings of impotence and helplessness (see Chestang, 1972; Seligman, 1975; Boykin, 1986). In fact, the specific coping processes required for people of color were acknowledged nearly a century ago by DuBois (1903) who suggested that American Blacks necessitated a virtual "double consciousness." The double consciousness referred to by DuBois was the dual status of being both American and Black. We further recognize the quandary of being American, Black, and male. In America, stereotypical male behavior takes on different meaning when related to Black males. Behavior which may be evaluated as daring, independentminded, or exciting when seen in majority culture (i.e., European American) males, may be seen as dangerous or threatening in Black males. Similar behavior takes on a different meaning. Anecdotally, parents share how they must instruct their young males, in particular, in how to respond properly to police. This child rearing ploy reduces the probability that their Black sons become victim to police brutality as a result of having their behavior misinterpreted as threatening or aggressive. Thus, minority parent child rearing efforts require, of necessity, providing explicit explanation of the meaning and significance of their youths' race, gender, and actions. American culture and the minority experience are themes explained to some sons by parents. However, such formally shared and stated explanations are not the norm (see Spencer, 1983, 1990), yet the dialectic and attendant tension of American culture still exist even when not made explicit. In the context of such a culture, youth having similar experiences can exhibit either resiliency or psychopathology. Thus, a phenomenological approach (i.e., how the individual perceives or makes sense of an experience) is useful in identifying specific points in need of intervention or support.

Combining a phenomenological approach with Bronfenbrenner's ecological systems theory provides a critical integration (Spencer, 1995). The integration affords a method for capturing the individual's ability to understand societal expectations, stereotypes and biases-even those that they themselves endorse or fulfill (Gordon \& Gergen, 1968). The synthesis also helps to acknowledge the critical and undergirding role of developmental changes in social cognition, multi-level social context character and content, and stage-relevant social experiences that differentially influence meaning making processes across the life course (Spencer, 1982, 1985). It is especially important to recognize meaning making processes during adolescence given the novel thought processes associated with that period which provide a degree of recursive thinking unavailable at earlier periods of development. Adolescence, using Lewis' (1995) model, would be a particularly salient time for critical aspects of self-organization to occur. Increases in social cognitive functioning occur that increase the amount and quality of information coming into the self-system-information that now has the added dimension of being about the self and even the self-organizing process. Added to this are the concurrent biological processes of maturation, puberty, hormonal and emotional fluctuations (e.g., Spencer, Dupree, Swanson, \& Cunningham, in press). Finally, the tendency for adolescents to be risk takers causing them to take in more, and to experience their environment more dramatically than previously is seen. 


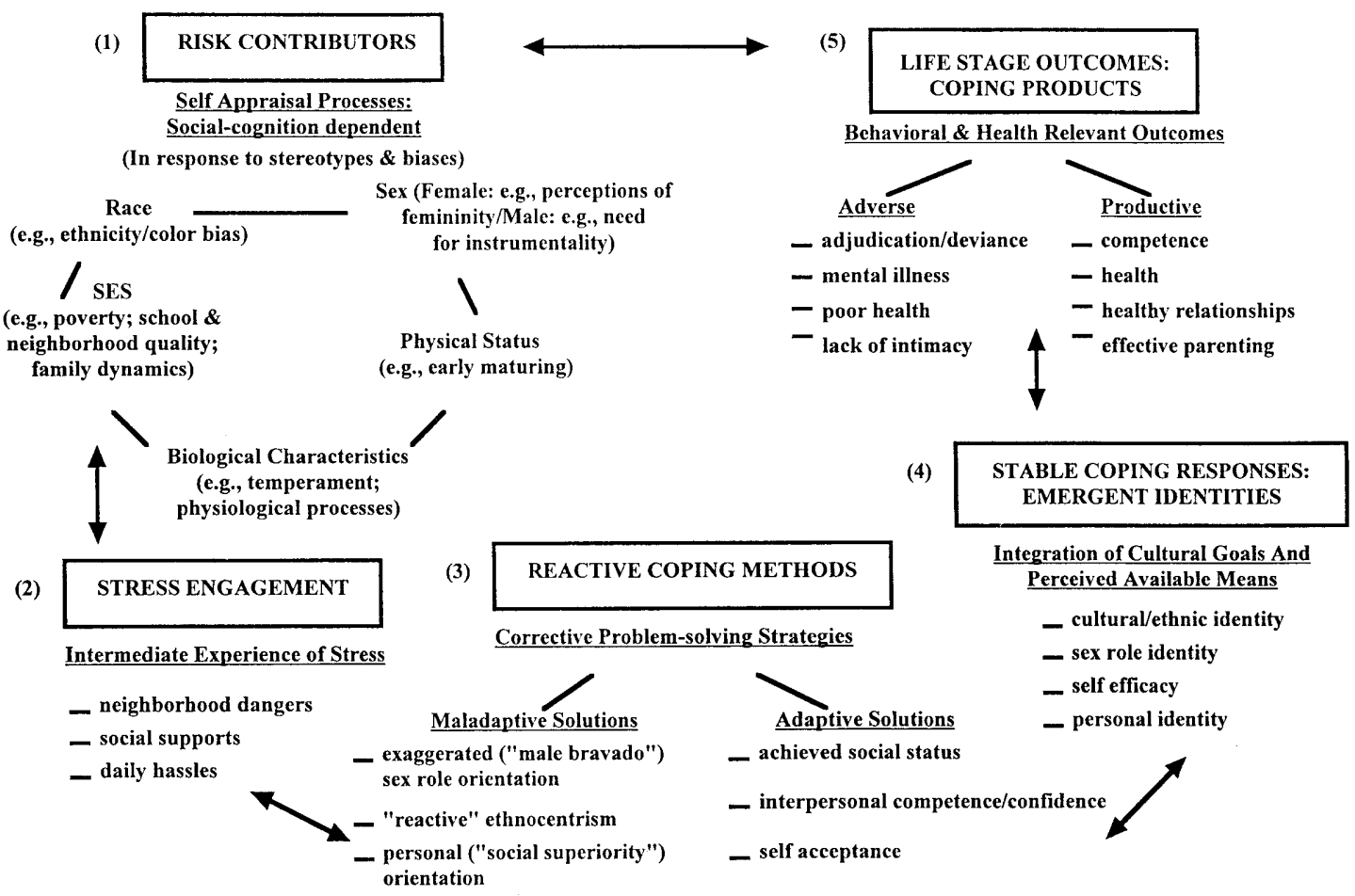

Figure 1. A Phenomenological Variant of Ecological Systems Theory (PVEST) (Spencer, 1995).

Swanson and Spencer (in press) and Kochman (1994) demonstrate the level of environmental risk quite dramatically for African-American adolescents generally; and Cunningham (1994) and Cunningham and Spencer (1996) illustrate the situation specifically for an unusually vulnerable group: African-American adolescent males. Thus, the amount, type, and frequency of changes in the life of the youth would be at an all time high and the rapidity and complexity of self-organization occurring at this time somewhat phenomenal. This perhaps explains why identity formation takes root at this stage as a virtual "safety net" against multiple opportunities for maladaptive reactive coping methods in response to chronic and varied contexts of risk.

As described by Spencer (1995) and Spencer and Dupree (1996), illustrated in Figure 1, and suggested by Bandura's (1978) theorizing, self-system development is reciprocally determined from self-other appraisal processes (i.e., what one thinks others think about him or her). These recursive self-other evaluative processes appear to be unavoidably linked to the experience of stress. Stressful situations require a response. In turn, one must determine whether a reactive coping response had its intended effect. Often we look to others to monitor ourselves and our actions (e.g., Do others' actions or behaviors change? Do others' behaviors or feelings towards us change?). The experience of stress requires coping which may be of two kinds: reactive coping methods and stable (psychosocial) coping responses. Figure 1 illustrates that reactive coping methods may be of two types: maladaptive solutions to the dilemma of stress engagement or adaptive solutions. Both are intended to be corrective problem solving strategies although the solutions are qualitatively distinct. As indicated in Figure 1, an unavoidable, reciprocal, and bidirectional linkage exists between the two coping responses: reactive coping methods and stable (psychosocial) coping responses. Reactive coping methods (e.g., withdrawal) and stable (psychosocial) coping processes (e.g., Euro- 
centric cultural identity) are linked to a coping outcome or product which may be either productive in quality (e.g., competency or self efficacy and resiliency) or unproductive (e.g., school-leaving/dropout). These coping outcomes along with ongoing self-other socialcognition linked appraisal processes influence subsequent experiences as the individual progresses across the life course (see Spencer, 1995; Spencer \& Dupree, 1996; Dupree, Spencer, \& Bell, in press). In sum, the individual is engaged in a life course process of unavoidable stage specific appraisal processes, series of environmental challenges (e.g., risks and stress) that are linked to diverse sociocultural contexts (e.g., expectations, attitudes, cultural beliefs and assumptions), and normative developmental tasks (see Havighurst, 1953).

\section{Comparisons of PVEST and Self-Organization Perspectives}

Cicchetti and Tucker (1994) emphasize the "individual's active strivings for self-organization as the major determinant of ontogenesis." For them, self-organization leads development from "a state of relative globality and lack of differentiation to a state of increasing differentiation, integration, articulation and hierarchic integration." Resilience is defined from the self-organizational perspective as the "ability to utilize self-righting tendencies" during sensitive periods or in response to negative feedback as in Cicchetti et al.'s (1993) study of maltreated children (Cicchetti \& Tucker, 1994, p. 534). For instance, a youth who is generally perceived as quiet and withdrawn may similarly think of himself as shy. However, with more experiences, interactions, and feedback in different contexts, the child may develop a more differentiated understanding of himself. The youth may recognize the contexts (e.g., people, places, activities) in which he is more quiet and reflective versus those contexts where he is more outgoing and engaging. Consequently, the youth develops his ability to use self-righting tendencies such as avoiding certain people, places, or activities, downplaying or emphasizing the importance or value of certain people, places, or activities. The youth may even learn how to capitalize on the perception of being quiet and reflective when it is associated with other traits that are valuable in different contexts. For instance, a child of few words who is also above average in size compared to peers may not need to be particularly verbose if physical stature is associated with fighting or athletic ability. On the other hand, in a classroom setting, an African-American female of few words may be perceived as a good student merely because she is not a behavior problem. The point is that self-organization is determined not only by context (e.g., home, school, community) but by the phenomenological experience of race, gender, physical status, and many other potential factors.

According to Lewis (1995), emotional and/ or cognitive appraisals of the environment influence the moment to moment patterns of self organization. Stability in an individual is recognized when situational response patterns become personality structures. Change in the self-system is explained by perturbations in the life of the individual. These perturbations include changes in the environment or the individual such as cognitive development or puberty. Significant perturbations or those that occur at particularly sensitive periods cause disequilibrium. New experiences-including new thoughts and emotions-must be integrated. The PVEST expands on this self-organization perspective by nesting the self in the larger micro- and macro-systems and illuminating the impact of feedback from the environment, particularly related to individual differences of race, class, skin color, gender, and maturational differences. The emphasis provides a more enhanced interpretation of interactive effects of culture and context with life-span ontogenesis.

\section{Environmental risks/stress engagement: Perturbations/negative feedback to the system}

Recurring experiences of the same feedback and stress can cause the individual to repeatedly reorganize in response to environmental 
conditions. Feedback and repeated response patterns would crystallize into personality structures, particular developmental trajectories, and identity. What does this mean if the individual is living in, as Chestang (1972) states, a hostile environment, experiencing chronic and negative feedback loops and the stress of poverty and violence on a daily basis? Lewis (1995) offers that when an individual receives negative feedback, the use of a defense mechanism is required for the individual to continue functioning in a way that does not threaten his or her ability to see him or herself as valued in different contexts. Thus, African-American students experiencing negative feedback about the self in school might shut off from this critically important experience. This decision may result in the diverting of psychic energy and attention to their peer group and reorganizing themselves or more closely attaching to a group which provides positive, or at least less threatening, feedback. The decision-which could lead to problem behaviors, school drop-out, and delinquency-may be of help in the short term in preserving the self, although, exponentially troubling efforts for mastery and competence in the long term. Consequently, behaviors that may lead to resilient appearing outcomes in the short term, however, may lead to pathological outcomes in the long term. Pathology occurs when the self-system "shuts down" in a sense, becomes reactively organized around negative feedback about the self, does not fully integrate all components, or becomes dependent upon maladaptive solutions as "selfrighting tendencies" as its major corrective problem-solving strategy. This differs from effective coping - the use of adaptive solutions as one's corrective problem-solving strategy; when repetitively used as stable coping responses, the outcome is an achieved identity or set of healthy psychosocial processes that undergird the probability of productive life-stage coping products.

As a demonstration of the PVEST model as an extended self-organizational perspective and as illustrated in Figure 2, in this paper we explore a model predicting negative academic learning attitude. The model includes a partic- ular risk (female headship) and two levels of stress engagement. Female headship is believed to be a pre-existing risk contributor and is included in the model as a control for any possible differences based on family structure. The first level of stress engagement is a selfreport of whether the adolescent experienced certain stressful events within the past year (stressful events). Cumulative stressful experiences have been found to have a synergistic effect which couples with other experiences that draw on the cognitive resources of adolescents; accordingly, it also was included in the model as a control to account for differences based on the number of stressors one must deal with. The second level of stress engagement (perceived social supports) is more concerned with the phenomenological experience of stress and includes perceived positive teacher expectations for black males, perceived popularity with peers, and perceived unpopularity with peers. It is assumed that the less social support one perceives from teachers and peers, the more negative learning attitude one will exhibit as a stable coping response or emergent identity. The model also includes an adaptive (vs. maladaptive) reactive coping method, generally positive attitude, suggested as a mediator variable (refer to Figure 2). It is assumed that a general positive attitude can mediate the relationship between perceived social supports (i.e., the source of stress) and negative learning attitude (i.e., the stable [psychosocial linked] coping response. That is, the higher the general positive attitude, the lower the negative learning attitude. Negative learning attitude represents an emergent identity in this model and stable coping response to stress. The assumption is that the adoption of a negative learning attitude emanates from the repetitive use of particular corrective problem-solving strategies: for example, involved is the frequent employment of maladaptive solutions or infrequent use of adaptive solutions (i.e., in this case infrequent use of a general positive attitude) in the face of perceived social supports or lack thereof. Accordingly, a negative learning attitude is suggested as a stable coping response or emergent identity that serves to maintain a 
(1)

RISK CONTRIBUTORS

Self Appraisal Processes:

Social-cognition dependent

(In response to stereotypes $\&$ biases)

FEMALE HEADSHIP

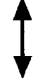

(2)

$$
\text { STRESS ENGAGEMENT }
$$

Intermediate Experience of Stress

- STRESSFUL EVENTS

Perceived social supports

- PERCEIVED POSITIVE

TEACHER EXPECTATION

FOR BLACK MALES

- PERCEIVED POPULARITY WITH PEERS

- PERCEIVED UNPOPULARITY WITH PEERS

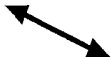

(4)

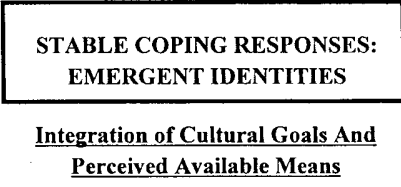

NEGATIVE LEARNING ATTITUDE

(3)

\section{REACTIVE COPING METHODS}

Corrective Problem-solving Strategies

GENERAL POSITIVE ATTITUDE

(Adaptive Solution)

Figure 2. Model of relationship among female headship, stressful events, perceived social supports, general positive attitude, and negative learning attitude.

"positive view of themselves" as perceived by particular adolescents. Importantly, the implications of a negative learning attitude as an emergent identity include a devaluing of learning activities as well as a diminished role of academics in such youths' experiences.

Accordingly, the analyses explore two hypotheses. First, an inverse relationship is expected between having a general positive attitude and the stable (psychosocial) coping response: negative learning attitude. Second, for this sample of African-American adolescent males, specifically two of the perceived social support predictor variables (i.e., perceived positive teacher expectations for black males, and perceived unpopularity with peers) are expected to be significant contributors to the prediction of negative learning attitude; the direction of effects for the two variables (i.e., perceived positive teacher expectations for black males, and perceived unpopularity with peers) is expected to be negative and positive, respectively.

\section{Methods}

Sample

The sample of 266 students was comprised of 181 African-American adolescent males and 85 females from a southeastern metropolitan area who represented a subsample of youths participating in a longitudinal study. The students were participants in the Promotion of Academic Competence (PAC) Project (Spencer, 1989). Data reported are from the third year (1991-1992) of a longitudinal data set (1989-1994) when participants were generally in the 8th, 9th, and 10th grades; however, because of the high retention rates for African-Americans in the school districts from which these students were drawn, the participants' ages ranged from 14 to 17 . The students were enrolled either in one of four middle schools in the same geographical area or had been promoted to one of approximately 10 metropolitan senior high schools. The student populations of three of the four middle 
schools where the students were originally sampled were over 90\% African-American; over $60 \%$ of the students in the fourth middle school were African-American. From parentreported family income information, it was determined that $58 \%$ of the subjects' families met federal poverty guidelines. The majority of the high schools were similar in demographics: majority African-American.

As indicated by the hypotheses, two questions were explored in the demonstration of the PVEST framework illustrated in Figure 1. The contribution of different types of intermediate experienced stress for the prediction of a negative learning attitude is examined. Relatedly, the role of an adaptive corrective problem-solving strategy, general positive attitude, as a reactive coping method is explored as the model's mediator variable. The issue of understanding the etiology of negative learning attitudes or "oppositional school attitudes" as described by Fordham and Ogbu (1986) endures as a critically important concern. Particularly for American youth, schooling continues to be a decisive variable for the maximization of life course earnings and more generalized manifested competence. Academic success is particularly salient in the case of intergenerationally and chronically impoverished urban African-American youths for whom inherited wealth is generally not a relevant resource and issue.

The set of stress engagement variables (i.e., perceived social supports) investigated focused on youths' perceptions of teachers' and peers views of them: Perceived positive teacher expectation for Black males, Perceived Popularity with Peers, and Perceived Unpopularity with Peers (refer to Figure 2).

In sum, as illustrated in Figure 2, the hypotheses explore the role of risk and stress factors and a reactive coping method for the prediction of negative learning attitude, conceptualized as a stable coping response, in a sample of African-American middle-late adolescents (i.e., 14-17 year olds).

\section{Measures}

Female headship was measured using a dichotomous variable. A home was designated as female headed if there was neither a husband or live-in boyfriend present in the home.

The Life Event Record (Coddington, 1972) is a 40-item list of events to which the respondent indicates whether or not they have occurred in the past year. Sixteen additional items were added to the original measure to further identify potential events experienced by inner city youth (Spencer, 1989). As these additions make this measure significantly different from the original, the data it yielded were subjected to principal components factor analysis-with the exception of two gender-specific items which were deleted (McDermott \& Spencer, 1995b). Cattell's scree permitted retention of two factors, but only a one factor solution yielded a factor that was reliable across gender and time with loadings that were .35 or greater. The factor could be considered a general scale of Stressful Events reported for the past year.

The Perceived Positive Teacher Perception (PPTP) and Perceived Negative Teacher Perception (PNTP) Scales (McDermott \& Spencer, 1995c) are derived from the Abbott Adjective Checklist (AAC) (1981). The AAC is a 35-item measure that asks the respondent how the "typical teacher" perceives the student in areas such as attitude, disposition, and behavior. The AAC was developed to identify perceived teacher perceptions. Data were obtained for the rescaling project from years 3 and 4. Half of the items were phrased positively and the other half were phrased negatively. Likert-scale responses included "all the time," "sometime," and "never." In the original measure (Abbott, 1981) "all the time" was associated with item 1 and "never" was associated with item 3 . To ensure directionality reflected endorsement, the anchors were revalenced so item 3 was associated with "all the time" and item 1 was associated with "never."

Analyses were conducted to ascertain whether a single bipolar dimension could substitute for the two countervalenced dimensions. For these analyses the 35 original items were revalenced so the higher numbers would reflect positive perception. This revalencing process produced redundancy in item variables; therefore, one of the two item variables was removed from subsequent analyses. Sepa- 
rate analyses were run to identify the utility of a multidimensional or unidimensional measure.

Squared multiple correlations were used on items from year 3 to produce initial communality estimates. Cattell's scree permitted the extraction of three factors. The theoretical assumption being tested, that AAC was meant to produce two dimensions, limited Cattell's scree to two factors. The varimax and promax rotation model yielded a maximal simple structure and coverage after defining a salient item loading at .40. Interfactor correlation for unit-weighted scores was acceptably low (-.41 to -.44). Item content and pattern of the factor loadings led to the naming of the first factor as PPTP and the second factor as PNTP. Internal consistency for PPTP, as measured by Cronbach's $\alpha$, was uniformly high overall, within sexes, and across years: for year 3 data, overall $\alpha=.90$ (338), males' $\alpha=$ .89 (232), females' $\alpha=.91$ (106). Additionally, the internal consistency for PNTP was consistently high: overall $\alpha=.87$ (338), males' $\alpha=.85$ (232), females' $\alpha=.90$ (106). Raw scores were converted to area $T$ scores through the weighted sum of salient items for year 3. Year $4 T$ scores were the result of computations from year 3 look up tables and year 4 raw scores (see McDermott \& Spencer, 1995c).

The Composite Perceived Positive Teacher Perception upon common factoring produced loadings $\geq .40$. In addition, it was found to be highly reliable overall across years and sexes: overall $\alpha=.91$ (338), males' $\alpha=.90$ (232), females' $\alpha=.92$ (106). Using $T$ scores, as derived from raw scores, the Composite dimension correlated at .87 (year 3) and .89 (year 4) with PPTP and -.75 (year 3) and -.71 (year 4) with PNTP.

Cross-year stability ranged from .41 for PPTP to .47 for PNTP and .45 for the unidimensional model.

The "Self" Sociometric Pupil Evaluation Inventory (SSPEI) is a 35-item, self-report measure intended to appraise possession of particular characteristics as perceived by others. The SSPEI stems ask questions relating to behavioral, dispositional, and physical aspects. A 5-point Likert scale, ranging from 1 for "No" to 5 for "All," allowed the respondent to indicate the number of people who would say the respondent possessed the particular qualities in question. Only AfricanAmerican subjects were used. Data were collected in year 3 .

The two-factor varimax and promax $(\kappa=$ 2) rotation defined .40 as a salient item loading. Interfactor correlation was appropriately low, $r=-.24$ (McDermott \& Spencer, 1995d). This model was subject to confirmatory, oblique, principal-components cluster analysis. Factor loadings suggested the labeling of the first factor Perceived Unpopularity with Peers and the second factor Perceived Popularity with Peers. Internal consistency, as measured by Cronbach's $\alpha$, for both Perceived Unpopularity with Peers and Perceived Popularity with Peers were .95 and .73 , respectively. Raw scores for the two dimensions were computed as the unit-weighted sum of salient items and then transformed to area conversion $t$ scores.

The Hare/Funder/Block Ego-Esteem/Resilience Scale (HFBEERS) is a self-report inventory intended to identify issues of selfesteem as well as ego resiliency. It is a combination of 30 items from the Hare Self Esteem Scale (HSES) (Hare, 1977) and 14 ego resilience questions devised by Block (1985). The HFBEERS was developed by simply inserting the Funder/Block questions amidst the HSES questions. To allow for continuity, the same 4-point Likert scale was used as used for the HSES (e.g., "strongly disagree," "disagree," "agree," and "strongly agree"). Wording for 15 HSES items were negative; wording for the remaining 15 HSES items and the 14 Funder/ Block items were worded positively. The valences for the negatively worded items were revalenced for convenience of interpretation. Only African-American subjects were used.

The variables used in year 3 were based on common factoring of the year 2 data (McDermott \& Spencer, 1995a). Responses to HFBEERS, for year 2, were submitted to exploratory common factoring using squared multiple correlations as initial communality estimates with Varimax rotation. Cattell's scree, and alternative tests, allowed retention of two or three factors, however, the third factor was 
not reliable across sex or year (i.e., year 3). The resultant two-factor solution indicated loadings of all positively worded items on one factor and negatively worded items on the other. To remedy this problem, only the 29 positively worded items were analyzed. Scree allowed retention of two factors, only one of which was reliable. The retained factor was named General Positive Attitude $(\alpha=.90)$. Raw scores for year 2 were transformed to area conversion $T$; year 3 scores were directly computed from year 2 look up tables.

The Scale of Teacher Expectations of Black Males (STEBM) is a self-report inventory designed to assess how the pupil interprets teacher expectation of self (McDermott \& Spencer, 1995e). This 12-item measure probed the respondent to answer questions pertaining to Black males in the manner they believed their teacher would respond (e.g., "Your teachers generally believe and feel that..."). This measure was piloted during year 3 of test administration for the Promotion of Academic Competence (PAC) project.

Data for PAC were available for years 3 and 4, using only African-American subjects. The scale used was a 4-point Likert scale. The original measure associated the value 1 with "Strongly agree" and the value 4 with "Strongly disagree." The presence of mostly positive items suggested the core component of the measure was to identify positive agreement with teacher expectancy. For this reason, the items were revalenced so that the value 1 was related to "Strongly disagree" and the value 4 was related to "Strongly agree." One of the 12 items was worded negatively whereas the other 11 were phrased positively. The negatively phrased item was analyzed for utility in both the original and revalenced version.

Cattell's scree, on year 3 item variables, permitted extraction of only one factor. Promax and varimax rotations were performed, in an attempt to extract at least two factors, but all subsequent factors were unreliable. The pattern and content of the factor loadings led to the naming of the factor the Perceived Teacher Expectancy for Black Male Students (McDermott \& Spencer, 1995e). Internal consistency overall, within sexes, and across years was consistently high (as measured by Cronbach's $\alpha$ ).

Results for year 3 were as follows: overall $\alpha=.84$ (362), males' $\alpha=.82$ (252), females' $\alpha=.86$ (110).

Raw scores for the dimension were computed as the unit-weighted sum of salient items and then transformed to area conversion $T$ scores at year 3. $T$ scores for year 4 were computed from the resultant year 3 look-up tables and year 4 raw scores. Cross year correlation for the Perceived Teacher Expectancy for Black Male Students dimension was .43. This implies that the construct is more of a state than a trait concept.

Each of the analyses was a setwise regression. Alpha level for entry into the regression models was set at .9999 . Four sets of variables were created: risk, stress, reactive coping processes, and stable coping processes. The risk and stressful events variables were forced into the model first as control variables. Each remaining set entered the model based on its significance level. As applied to address the noted hypothesis, after controlling for risk and stressful events, perceived social support variables and reactive coping method were entered for predicting the unique variance accounted for by each set in the prediction of student's negative learning attitude.

\section{Results}

Sets of setwise regressions by gender determined the proportion of variance in students' self-reporting of negative learning attitude that could be accounted for separately by different sets of self-organizing variables characterized as perceived social supports and reactive coping method. As indicated in Figure 2, the reactive coping variable was general positive attitude. Figure 2 lists the perceived social supports variables as perceived positive teacher expectations for Black males, unpopularity with peers, and popularity with peers.

Although testing the same predictive model, analyses were conducted separately by gender. Table 1 lists mean differences by gender which suggest that the girls see teachers actually having higher (perceived) expectations for black boys than the boys believe the teach- 
Table 1. Means and significance levels by gender for independent and dependent variables

\begin{tabular}{|c|c|c|c|c|}
\hline & \multicolumn{2}{|c|}{$\begin{array}{c}\text { Male } \\
(n=181)\end{array}$} & \multicolumn{2}{|c|}{$\begin{array}{l}\text { Female } \\
(n=85)\end{array}$} \\
\hline & $M$ & $S D$ & $M$ & $S D$ \\
\hline Female headship $^{a}$ & 0.23 & 1.00 & -0.00 & 1.00 \\
\hline Stressful life events & 53.3 & 8.45 & 54.4 & 9.30 \\
\hline $\begin{array}{l}\text { Perceived positive teacher } \\
\text { expectation for Black } \\
\text { males }\end{array}$ & $48.4 *$ & 10.91 & 51.9 & 11.13 \\
\hline $\begin{array}{l}\text { Perceived unpopularity } \\
\text { with peers }\end{array}$ & 49.6 & 9.8 & 47.89 & 9.26 \\
\hline $\begin{array}{l}\text { Perceived popularity with } \\
\text { peers }\end{array}$ & 48.5 & 9.49 & 50.2 & 11.43 \\
\hline General positive attitude & 48.3 & 10.04 & 51.0 & 11.16 \\
\hline Negative learning attitude & $49.9 *$ & 9.81 & 47.1 & 11.51 \\
\hline
\end{tabular}

${ }^{a}$ Female headship values actually represent $z$ scores. $* p<.05$.

ers have; the lower mean obtained for boys that report their views concerning teachers' perceptions of black male performance was significant although modest $(t=-2.48, p<$ $.05)$. Table 1 also illustrates that the boys held a higher and modestly significant negative learning attitude when compared with their female cohort $(t=2.03, p<.05)$.

\section{Correlation findings}

Consistent with the mean differences listed in Table 1, Table 2 suggests several patterned differences when examining the associations between the criterion variable, negative learning attitude, and the stress engagement variables for boys and girls. On the one hand, for boys stress is positively and quite significantly linked with a generally positive attitude $(r=.27, p<.001)$ ! The more stressful events experienced in the past year, the more generally positive attitude demonstrated. Similarly stress is negatively linked with a negative learning attitude $(r=-.30, p<.001)$ : More reported stress, less of a negative learning attitude. On the other hand, neither association is evident for girls.

Youths' perceived unpopularity with peers is linked to a less positive general attitude for boys and girls $(r=-.28, p<.001$, and $r=-.21$, $p<.05$, respectively). Similarly, youths' per- ceived unpopularity with peers is significantly and positively correlated with negative learning attitude: perceived unpopularity with peers, more negative learning attitude. The relationship is highly significant for boys and girls $(r=.47, p<.001$, and $r=.52, p<.001$, respectively). Finally, for both males and females, there is an association between having a generally positive attitude and negative learning attitude $(r=-.35, p<.001$, and $r=$ $-.28, p<.05$, respectively): A generally positive attitude for both boys and girls is associated with less of a negative learning attitude.

The specific associations between component members of the stress engagement variable set with the criterion variable, negative learning attitude, are best illustrated in the regression analyses reported in Tables 3 and 4 for boys and girls, respectively. Tables 3 and 4 suggest the gender-consistent finding that unpopularity with peers is the largest contributor to the variance explained for negative learning attitude. A noteworthy and patterned finding is consistent for boys across different steps in the regression analysis. Specifically, stress continues to have an independent effect, even as other variables are entered. It is also an unexpected, in fact, counter-intuitive finding: Stress is negatively linked with negative learning attitude. Apparent from the $F$ values reported in Table 3 for boys is the indepen- 
Table 2. Correlation matrices by gender

\begin{tabular}{|c|c|c|c|c|c|c|c|}
\hline & $\begin{array}{l}\text { Female } \\
\text { Headship }\end{array}$ & $\begin{array}{c}\text { Stressful } \\
\text { events }\end{array}$ & $\begin{array}{c}\text { Positive } \\
\text { Teacher } \\
\text { Black Male } \\
\text { Expectations }\end{array}$ & $\begin{array}{l}\text { Unpopularity } \\
\text { with Peers }\end{array}$ & $\begin{array}{l}\text { Popularity } \\
\text { with Peers }\end{array}$ & $\begin{array}{l}\text { General } \\
\text { Positive } \\
\text { Attitude }\end{array}$ & $\begin{array}{c}\text { Negative } \\
\text { Learning } \\
\text { Attitude }\end{array}$ \\
\hline \multicolumn{8}{|l|}{ Boys $(n=181)$} \\
\hline Female headship & 1.00 & & & & & & \\
\hline Stressful events & -0.03 & 1.00 & & & & & \\
\hline $\begin{array}{l}\text { Positive teacher Black } \\
\text { male expectations }\end{array}$ & -0.11 & 0.01 & 1.00 & & & & \\
\hline Unpopularity with peers & -0.08 & $-0.22 * *$ & 0.01 & 1.00 & & & \\
\hline Popularity with peers & -0.05 & 0.11 & 0.06 & $-0.20 * *$ & 1.00 & & \\
\hline General positive attitude & 0.04 & $0.27 * * *$ & 0.02 & $-0.28 * * *$ & $0.17 *$ & 1.00 & \\
\hline Negative learning attitude & 0.02 & $-0.30 * * *$ & -0.14 & $0.47 * * *$ & $-0.33 * * *$ & $-0.35 * * *$ & 1.00 \\
\hline \multicolumn{8}{|l|}{ Girls $(n=85)$} \\
\hline Female headship & 1.00 & & & & & & \\
\hline Stressful events & -0.08 & 1.00 & & & & & \\
\hline $\begin{array}{l}\text { Positive teacher Black } \\
\text { male expectations }\end{array}$ & 0.05 & -0.02 & 1.00 & & & & \\
\hline Unpopularity with peers & 0.12 & 0.03 & $-0.21^{a}$ & 1.00 & & & \\
\hline Popularity with peers & 0.08 & -0.11 & -0.05 & $-0.29 * *$ & 1.00 & & \\
\hline General positive attitude & 0.02 & 0.06 & -0.04 & $-0.21 *$ & $0.28 * *$ & 1.00 & \\
\hline Negative learning attitude & 0.06 & -0.12 & -0.17 & $0.52 * * *$ & $-0.29 * *$ & $-0.28 *$ & 1.00 \\
\hline
\end{tabular}

${ }^{a}<.10$.

$* p<.05 .{ }^{* *} p<.01 . * * * p<.001$.

Table 3. Regression of negative learning attitudes on female headship, stressful life events, perceived social supports (positive teacher expectation for Black male students, perceived unpopularity with peers, perceived popularity with peers), and reactive (adaptive) coping method (general positive attitude) (Boys $\mathrm{n}=181)$

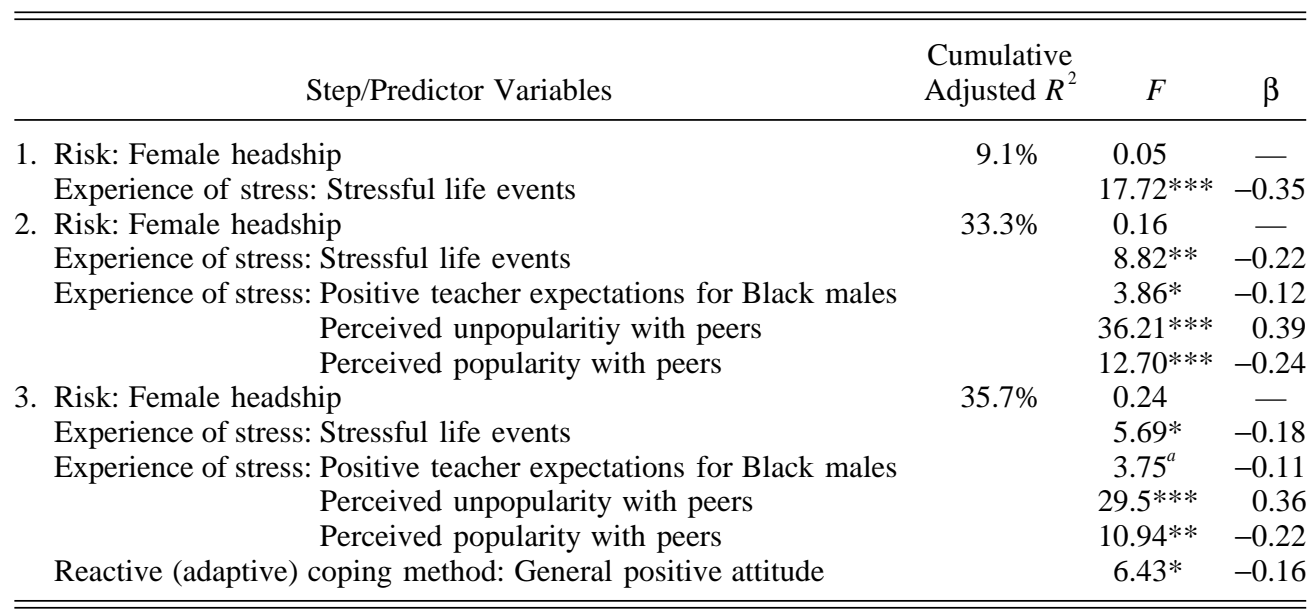

${ }^{a}<.10$.

$* p<.05 . * * p<.01 . * * * p<.001$. 
Table 4. Regression of negative learning attitudes on female headship, stressful life events, perceived social supports (positive teacher expectation for Black male students, perceived unpopularity with peers, perceived popularity with peers), and reactive (adaptive) coping method (general positive attitude) $($ Girls $\mathrm{n}=85)$

\begin{tabular}{|c|c|c|c|}
\hline Step/Predictor Variables & $\begin{array}{l}\text { Cumulative } \\
\text { Adjusted } R^{2}\end{array}$ & $F$ & $\beta$ \\
\hline 1. Risk: Female headship & $1.6 \%$ & 0.21 & - \\
\hline Experience of stress: Stressful life events & & 1.04 & - \\
\hline 2. Risk: Female headship & $32.4 \%$ & 0.01 & - \\
\hline Experience of stress: Stressful life events & & 2.54 & - \\
\hline Experience of stress: Positive teacher expectations for Black males & & 0.88 & - \\
\hline Perceived unpopularity with peers & & $20.27 * * *$ & 0.56 \\
\hline Perceived popularity with peers & & $3.31^{a}$ & -0.18 \\
\hline 3. Risk: Female headship & $34.1 \%$ & 0.02 & - \\
\hline Experience of stress: Stressful life events & & 2.12 & - \\
\hline Experience of stress: Positive teacher expectations for Black males & & 1.05 & - \\
\hline Perceived unpopularity with peers & & $18.14 * * *$ & 0.54 \\
\hline Perceived popularity with peers & & 2.11 & - \\
\hline Reactive (adaptive) coping method: General positive attitude & & 1.99 & - \\
\hline
\end{tabular}

dent and multifaceted impact of social support on negative learning attitudes. The contribution of each is in the expected direction. Only perceived unpopularity with peers is positive: Perceived unpopularity with peers positively contributes to negative learning attitude. The findings for girls are similar only for one social support variable: Perceived unpopularity with peers is positively linked with the prediction of negative learning attitudes, $p<.001$. Not surprising, girls' reports of positive teacher expectations for Black males was unrelated to their own negative learning attitudes. For boys, although only trend level, their perceptions of positive teacher expectations for black males suggests a patterned (trend level only) association with negative learning attitudes. The finding is in keeping with adolescents' heightened awareness of others' views of them. In this case, the importance is of lifecourse quality since a commitment to school and effectance motivation increases the likelihood of competence, secondary school completion, the likelihood of postsecondary schooling options and life-long gainful employment.

Unlike the highly significant linkage between perceived popularity with peers and the criterion variable obtained for boys $(p<$
.001), although also negative, the relationship obtained only trend level for girls (see Table 4). Also notable for boys is the independence of the reactive coping method, general positive attitude, after controlling for stress and social supports.

\section{Discussion}

As initially stated, one of the important strengths of coupling a phenomenological perspective with an ecological systems approach is that it affords a more dynamic, culturally responsive, context-sensitive perspective for interpreting the individual's own meaning making process: It captures the individual's intersubjectivity. The perspective is particularly important for understanding the school experiences of African-American adolescents. The significant physical, cognitive, physiological, and emotional normative changes associated with adolescence make the period, in and of itself, an unusual source of disequilibrium for a critical developmental transition as youth prepare themselves for a successful passage into adulthood. In American society, academic competence is an important foundational component for successful adulthood and, in fact, life course competence. Thus, ex- 
periences had in the school context that leave students feeling disfranchised and/or lead to school drop out or delinquency must be recognized. The school context continues to be a source of special challenge for youth of color and economically disadvantaged teens. Understanding youths' subjective processes and their relationship to academically significant outcomes are of critical importance (Fordham \& Ogbu, 1986). Adolescent attitudes toward learning represent a critical outcome variable and was the criterion measure for the study in light of the long-recognized relationship between poor school performance and problem behaviors (e.g., Took \& Weiss, 1994).

All measures were student reports for self or student perceptions of teachers and peers. As indicated by Figure 2, in this paper we attempt to couple risk/stress variables with a reactive (although adaptive) coping method, general positive attitude, for the prediction of a stable coping response: negative learning attitude. In addition to stressful events, a set of perceived social support variables were included as other stress factors: perceived positive teacher expectation for Black males, perceived popularity with peers, and perceived unpopularity with peers (see Figure 2).

The general goal of the hypotheses tested was to explore the etiology of adolescents' negative learning attitudes. The first hypothesis explored the efficacy of the reactive coping method, general positive attitude, as a contributor variable in the prediction of negative learning attitude. The second hypothesis explored whether two of the three perceived social support variables (i.e., perceived positive teacher expectations for Black males and perceived unpopularity with peers) were the most salient in the prediction of negative learning attitude.

Evident from Tables 3 and 4 is that female headship was not a significant predictor for males or females. From a phenomenonological perspective, family structure alone would not necessarily explain differences in psychological states such as negative learning attitudes. Rather, PVEST suggests that the selfappraisal processes that the adolescent makes with respect to his or her family's structure will have greater influence than the family structure itself. Nevertheless, other factors were significant contributors in the prediction of negative learning attitude. For girls, as reported in Table 4, after controlling for risk and stressful events which were not significant, perceived unpopularity with peers was the single significant contributor to girls' negative learning attitude. Unexpected was that stress experienced was of total unimportance for negative learning attitudes for girls given its unmistakable salience and consistent importance across steps of the regression for boys. Given the singular importance of unpopularity with peers for negative learning attitudes in the case of girls, on the one hand, the regression finding might suggest a special sensitivity to perceptions of unpopularity with peers for girls versus boys. On the other hand, the significance of both unpopularity and popularity with peers in predicting negative learning attitudes for boys might, in fact, suggest their broader and undifferentiated responsivity to peer evaluative feedback; importantly, it provides significant opportunities for intervention/prevention supports. Further, in the case of girls, if the stress measure had been heavily weighted for assessing peer-specific stress, might there have been an equally important predictive relationship between stress and negative learning attitude across the different steps? Perhaps the findings suggest broader, generic sources of importance (in fact, academically non-marginalizing?) in the lives of males versus females. More physiologically and health-relevant theorizing concerning sex differnces suggest greater undifferentiated and life-course associated vulnerability to stress for males when compared to females (Wingard, 1987). In fact, hypotheses about the greater longevity of females in general have been linked to their life course development and use of same-sex relationships as opposed to men's greater reliance on oppositesex (i.e., marital) bonds. In sum, the salience of unpopularity and popularity with peers for boys and the singular significance of unpopularity with peers for girls might, in and of themselves, represent different etiologies.

There were other interesting differences for boys (refer to Table 3). First, stressful life 
events were highly important for males in the prediction of negative learning attitudes in an unexpected direction: more stress was a significant predictor of a less negative learning attitude. Stressful life events continued to contribute across steps with a negative beta at each of the subsequent steps of the regression equation. The pattern may mean, as suggested, that boys who experience a significant amount of stress in their lives stay more engaged in the schooling process, are less marginalized and "invisible" and, consequently, have a less negative learning attitude. Although a qualitative analysis of experiences was not done, this unexpected predictive relationship might imply that for males, in particular, stressful events may be a proxy for the lack of marginalization. That is, youth may be heavily engaged in social activities which also result in significant opportunities for stressful events. Certainly data obtained for girls suggest their greater classroom centrality when compared to Black males (see Irvine, 1990).

Independent of gender, perceived social supports, specifically perceived unpopularity with peers, accounted for a significant amount of variance for youths' negative learning attitude. As suggested, over a third of the variance for negative learning attitude for girls was accounted for by the sole significant contributing variable: perceived unpopularity with peers (refer to Table 4). The prediction model for boys is especially important since it presents many more opportunities for intervention strategies and social supports. For example, reporting few significant life events may suggest marginalization and may be important in the acquisition of negative learning attitudes. Additionally, all three perceived social supports were significant contributors. Perceiving that teachers hold positive expectations for Black males is associated with less negative learning attitudes. Similarly, a perception of being popular with peers is associated with a less negative learning attitude. On the other hand, like the findings for girls, the perception by boys that they are unpopular with peers is a significant predictor of negative learning attitude. Further, even though just marginally significant $(p<.05)$, the reactive (adaptive) coping method, having a generally positive attitude, is related to a less negative learning attitude for boys (refer to Table 3).

Resilience is only recognized in the context of adverse or stressful experiences. Having a generally positive attitude is suggested as an effective reactive (although adaptive) coping method. It is used as an adaptive corrective problem-solving strategy in the face of challenge which helps a person to move through the adverse circumstance through the use of a strategy, perhaps, that keeps one "upbeat" and positive. In fact, the findings for boys provide support for the first hypothesis that explored the importance of that coping method for learning attitude. The finding for boys, in fact, was in the expected (inverse) direction: less evident use of positive attitude as a reactive coping method is associated with a negative learning attitude. Consequently, the modest although significant contribution of a positive learning attitude to youths' negative learning attitude may suggest that, to some extent, boys' have learned to perceive certain experiences-that would be highly stressful or discouraging for others - as a part of everyday experience (i.e., merely something else or one more challenge). There may be events that occur so consistently that some youth use reactive (adaptive) coping responses developed, adopted, and modeled by members of the community and which may, for some, cast the experiences themselves in a more positive light. That is, the sheer prevalence of specific challenges prevents a more personalized internalization of affect. On the other hand, other students may lack exposure to models who make frequent use of reactive coping methods that are adaptive and, instead, are exposed to models who use more maladaptive problem solving strategies; and, as a consequence, such youths may take on a stable coping response (e.g., negative learning attitude) which has deleterious behavioral correlates and adverse coping products (e.g., school failure and school leaving).

Understanding youths' perceptions and reactive coping methods to experiences such as having a parent with a drug problem, living with parental rancor and divorce, becoming involved with or being exposed to drugs or 
alcohol, attending schools that are alienating, and having increased conflict with parents are all chronic, context-linked stresses that require reactive coping methods. The relationship between stressful events and adaptive corrective problem strategies (e.g., general positive attitude) deserves further inquiry. Furthermore, PVEST suggests a reciprocal relationship between perceptions and attitudes.

Specifically and consistent with a phenomenological analysis, our perceptions of how others perceive us can influence our expectations, responsive attitudes and behaviors. This is complicated by the fact that our attitudes and behaviors can influence how others perceive, respond, and react to us. Therefore, in considering the meaning of the findings from this study, it is important to keep in mind that this study focused on cognitive variables concerned with perceptions and attitudes. Except for a report of stressful events experienced in the past year, no behavioral variables were included that would indicate whether negative peer perceptions were, in fact, unfounded or not for any given student. Nevertheless, PVEST suggests that perceptions are important as a source of stress and can influence behavior even when they are not based necessarily "in fact." Therefore, if lack of acceptance or positive perception by teachers in the school context leads to youths' disfranchisement from the schooling process, the focus of students' perceptual processes may represent an important and necessary focal point for intervention efforts.

As an intervention strategy to address adolescent problems, there has been significant national interest in the supportive role of mentoring. Our findings indicate that, particularly for males, youths' perceptions of teachers are critically important as a source of stress. The predictive pattern for males suggest the need for adult role models and supportive adults in the lives of youth who provide models of adaptive corrective problem-solving strategies (e.g., general positive attitude). Furthermore, interventions that focus on either perceived or real peer relations suggest other potentially important pathways for enhancing youths' school engagement through the internalization of a less negative learning attitude.
There was partial support for the second hypothesis which suggested that perceived positive teacher expectations for Black males and perceived unpopularity with peers would be the most important contributors to negative learning attitude. Table 3 indicated that the largest contributor was perceived unpopularity with peers; although, equally salient was perceived popularity with peers. Positive teacher perceptions was modestly significant for boys. On the other hand, for girls, only perceived unpopularity with peers significantly and consistently predicted negative learning attitude. The finding that perceived unpopularity with peers, for girls, represents the single significant predictor of negative learning attitude is consistent with other research demonstrating that female peer groups are especially important and different from male peer groups. As suggested, across the life course, social relationships appear to be unusually salient for health: physical and mental. The centrality and salience of the peer group for girls is important for programs of health promotion and enhancement. However, for males, the findings suggest additional and multiple roots of support and intervention: teacher supports, training programs, and mentors as models of more adaptive corrective problem solving strategies (i.e., reactive coping methods). These data do not indicate nonpeer group potential resources for girls, however. Perhaps, for females, stressful events should be thought of more in terms of group as opposed to individual experiences. Furthermore, it may be the case that general positive attitude, for females, should be thought of in terms of how it could be influenced by peer relations.

The findings for this model suggest that, particularly and consistently for AfricanAmerican urban male teens, particular stresses are important in the prediction of negative learning attitude: positive teacher expectancies for Black males, perceived unpopularity with peers, and perceived popularity with peers; the relationships are in the expected direction. The reactive (adaptive) coping method, general positive attitude, appears to be an effective adaptive response to perceived unavailability of social supports as the source of 
stress in the prediction of the stable coping response: negative learning attitude. Having a generally positive attitude matters in the prediction of negative learning attitudes. The findings suggest its role as a singularly important and independent contributor for males' negative learning attitudes after controlling for risk, stressful events, and diverse sources of social support. In general, it is not a new notion that teachers and peers matter in the lives of youth (Irvine, 1988; Cunningham, 1994). However, analyses suggest that specifically perceived unpopularity with peers matter most for boys and girls; particularly for females, however, perceived popularity with

\section{References}

Abbott, A. A. (1981). Factors related to third grade achievement: Self-perception, classroom composition, sex, and race. Contemporary Educational Psychology, 6, 167-179.

Bandura, A. (1978). The self-system in reciprocal determinism. American Psychologist, 33(4), 344-358.

Block, J. (1985, October). Some relationships regarding the self emanating from the Block and Block longitudinal study. Paper presented at the SSRC conference, Center for Advanced Study in the Behavioral Sciences, Stanford, CA

Boykin, A. W. (1986). The triple quandary and the schooling of Afro-American children. In U. Neisser (Ed.), The school achievement of minority children: New perspectives (pp. 57-92). Hillsdale, NJ: Erlbaum.

Chestang, L. W. (1972). Character development in a hostile environment. Occasional Paper No. 3 (Series) (pp. 1-12). Chicago, IL: University of Chicago.

Cicchetti, D., Rogosch, F., Lynch, M., \& Holt, K. (1993). Resilience in maltreated children: Processes leading to adaptive outcome. Development and Psychopathology, 5, 629-647.

Cicchetti, D., \& Tucker, D. (1994). Development and self-regulatory structures of the mind. Development and Psychopathology, 6, 533-549.

Coddington, R. D. (1972). The significance of life events as etiologic factors in the diseases of children-II: A study of a normal population. Journal of Psychosomatic Research, 16, 205-213.

Cunningham, M. (1994). Expressions of manhood; Predictors of educational achievement and AfricanAmerican adolescent males. Unpublished doctoral dissertation, Emory University, Atlanta, GA.

Cunningham, M., \& Spencer, M. B. (1996). The Black male experiences measure. In R. L. Jones (Ed.), Handbook of tests and measurements for Black populations (pp. 301-307). Hampton, VA: Cobb \& Henry.

DuBois, W. E. B. (1903). Souls of Black folk. Chicago: McClury.

Dupree, D., Spencer, M. B., \& Bell, S. (in press). The ecology of African-American child development: Normative and non-normative outcomes. In G. John- peers does not seem as salient as their perceived unpopularity. Clearly all social supports are of special importance for males.

Overall, perceived social supports are critically important as a source of stress and are linked to cultural contexts amenable to intervention. As suggested, the predictive models may be helpful in the "fine tuning" of intervention methods that should result in better self-organizational outcomes and life course opportunity. As an interpretive device, the PVEST model provides an important framework for clarifying complex context-linked phenomena.

son-Powell \& Y. Yamamoto (Eds.), Transcultural child psychiatry: A portrait of American's children. Wiley.

Fordham, S., \& Ogbu, J. U. (1986). Black students' school success: Coping with the "burden of 'acting white." Urban Review, 18(3), 176-206.

Gordon, C., \& Gergen, K. J. (1968). The nature and dimension. In C. Gordon \& K. J. Gergen (Eds.), The self in social interaction (pp. 33-39). New York: Wiley.

Hare, B. R. (1977). Racial and socioeconomic variations in preadolescent area-specific and general self-esteem. International Journal of Intercultural Relations, 1(3), 31-51.

Havighurst, R. J. (1953). Human development and education. New York: McKay.

Irvine, J. J. (1990). Black students and school failure. New York: Greenwood Press.

Kochman, T. J. (1992). The relationship between environmental characteristics and the psychological functioning of African-American youth. Unpublished honors thesis. Emory University, Atlanta, GA.

Lewis, M. (1995). Cognition-emotion feedback and the self-organization of developmental paths. Human Development, 38, 71-102.

McDermott, P. A., \& Spencer, M. B. (1995a). Measurement Properties of Hare/Funder/Block Ego-Esteem/ Resilience Scale (years 2 and 3) in (Interim Research Report No. 8). Philadelphia, PA: University of Pennsylvania, Center for Health, Achievement, Neighborhood, Growth, and Ethnic Studies.

McDermott, P. A., \& Spencer, M. B. (1995b). Measurement properties of Revised Life Events Questionnaire in (Interim Research Report No. 9). Philadelphia, PA: University of Pennsylvania, Center for Health, Achievement, Neighborhood, Growth, and Ethnic Studies.

McDermott, P. A., \& Spencer, M. B. (1995c). Measurement properties of Revised Abbott Adjective Checklist in (Interim Research Report No. 25). Philadelphia, PA: University of Pennsylvania, Center for Health, Achievement, Neighborhood, Growth, and Ethnic Studies.

McDermott, P. A., \& Spencer, M. B. (1995d). Measure- 
ment properties of "Self" Sociometric Pupil Evaluation Inventory in (Interim Research Report No. 29). Philadelphia, PA: University of Pennsylvania, Center for Health, Achievement, Neighborhood, Growth, and Ethnic Studies.

McDermott, P. A., \& Spencer, M. B. (1995e). Measurement properties of Revised Scale of Teacher Expectations of Black Males in (Interim Research Report No. 26). Philadelphia, PA: University of Pennsylvania, Center for Health, Achievement, Neighborhood, Growth, and Ethnic Studies.

Seligman, M. E. P. (1975). Helplessness: On depression, development, and death. San Francisco, CA: Freeman.

Spencer, M. B. (1982). Preschool children's social cognition and cultural cognition: A cognitive developmental interpretation of race dissonance findings. Journal of Psychology, 112, 275-296.

Spencer, M. B. (1983). Children's cultural values and parental child rearing strategies. Developmental Review, 3, 351-370.

Spencer, M. B. (1985). Cultural cognition and social cognition as identity factors in Black children's personalsocial growth. In M. B. Spencer, G. K. Brookins, \& W. R. Allen (Eds.), Beginnings: The social and affective development of Black children (pp. 215-230). Hillsdale, NJ: Erlbaum.

Spencer, M. B. (1989). Patterns of developmental transitions for economically disadvantaged Black male adolescents. Proposal submitted to and funded by the Spencer Foundation, Chicago, IL.

Spencer, M. B. (1990). Parental values transmission: Implications for Black child development. In J. B. Stewart \& H. Cheatham (Eds.), Interdisciplinary per- spectives on Black families (pp. 111-130). New Brunswick, NJ: Transactions.

Spencer, M. B. (1995). Old issues and new theorizing about African-American youth: A phenomenological variant of ecological systems theory. In R. L. Taylor (Ed.), Black youth: Perspectives on their status in the United States (pp. 37-69). Westport, CT: Praeger.

Spencer, M. B., \& Dupree, D. (1996). African-American youth's eco-cultural challenges and psychosocial opportunities: An alternative analysis of problem behavior outcomes. In D. Cicchetti \& S. Toth (Eds.), Rochester symposium on developmental psychopathology: Vol. 7. Adolescence: Opportunities and challenges (pp. 259-282). Rochester, NY: University of Rochester Press.

Spencer, M. B., Dupree, D., Swanson, D. P., \& Cunningham, M. (in press). The influence of physical maturation and hassles on African-American adolescents' learning behaviors. Journal of Comparative Family Studies.

Swanson, D. P., \& Spencer, M. B. (in press). Developmental and cultural context considerations for research in African-American adolescents. In H. Fitzgerald (Ed.), Children of color: Research, health and public policy issues. New York: Garland Press.

Took, K. J., \& Weiss, D. S. (1994). The relationship between heavy metal and rap music and adolescent turmoil real or artifact? Adolescence, 29(115), 613-621.

Wingard, D. L. (1987). Social behavior and biological factors influencing the sex differential of longevity. Background paper prepared for the National Institute on Aging (NIA), Washington, DC. 